\title{
JOURNAL.RU
}

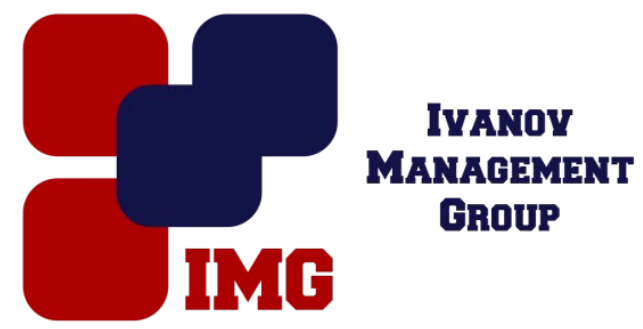

Буткай Д.В., Струков П. С., Суконщиков А.А., Бахтенко Е.А. Вологодский государственный университет

Вологда, Россия

doi: 10.18411/lj-31-01-2017-1-01

idsp 000001:lj-31-01-2017-1-01

\section{Задача поиска информационных ресурсов с применением подхода к обработке документов на синтаксическом уровне}

Рассмотрим задачу поиска информационных ресурсов. Заданы множество документов $D=\left\{d_{i} \mid i=1 \ldots n\right\}$, где $\mathrm{n}-$ количество документов коллекции, и описание информационной потребности q.

Требуется найти подмножество $\mathrm{R}$ множества документов $\mathrm{D}$, которое состоит из релевантных документов для запроса q - результирующее множество.

Кроме текстовых документов также может выполняться поиск мультимедийных ресурсов (изображений, аудиозаписей, видеороликов и т.п.). Однако для этого требуется создавать текстовые описания, которые включаются во множество документов D в качестве входных ресурсов.

Описание процесса поиска информации представлено на рис. 1.

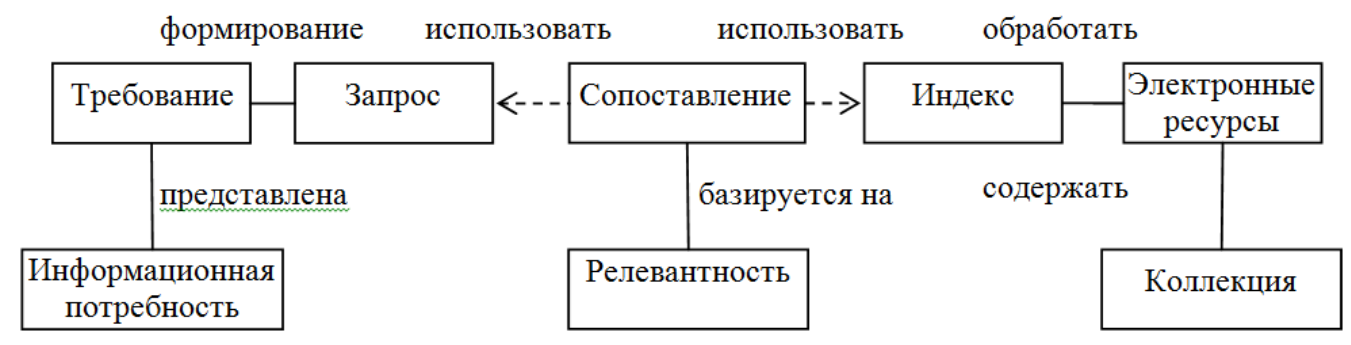

Рис. 1. - Процесс поиска информации

С одной стороны, у человека-пользователя есть информационная потребность, представляемая некоторым требованием, которое затем преобразуется в запрос. С другой стороны, в поисковых северах имеются коллекции электронных ресурсов, которые индексированы для цели выполнения поиска. В результате обработки запросов поисковые серверы возвращают множество релевантных документов пользователям. 
В настоящее время существует большое количество поисковых систем. Однако все они имеют общую архитектуру, которая представлена на рис. 2.

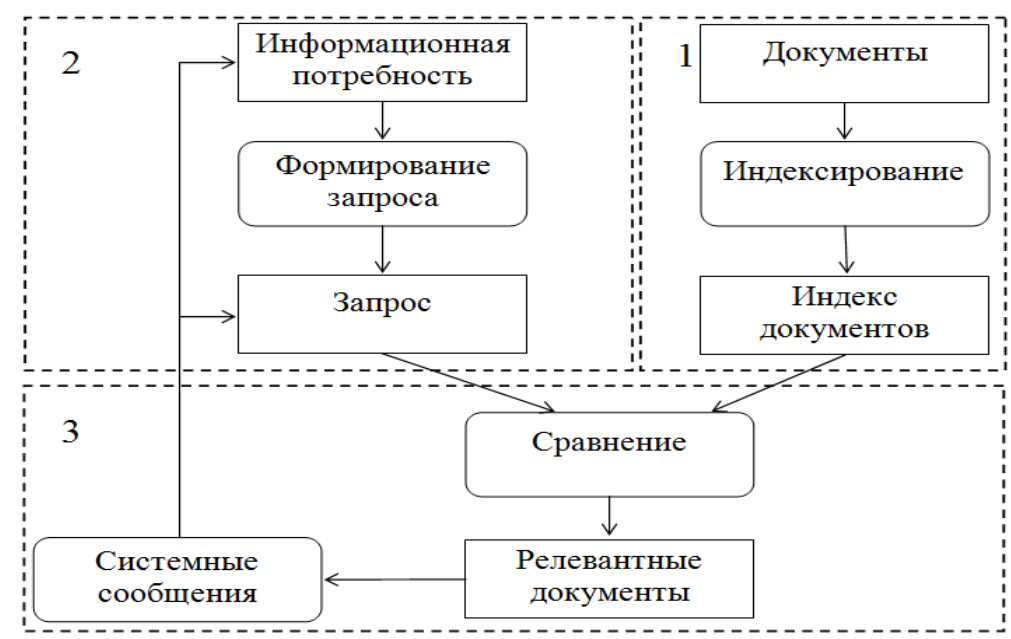

Рис. 2. - Общая архитектура систем информационного поиска

Как показано на рис. 2 любая система информационного поиска выполняет следующие три базовые функции:

1) Индексирование - сбор электронных ресурсов и создание их логических представлений, а также хранение этих представлений с использованием индексов (оптимизированных структур данных для быстрого выполнения поиска).

2) Формирование запросов - описания информационных потребностей пользователя на языке, поддерживаемом поисковой системой.

3) Сравнение - вычисления оценок близости (релевантности) между запросами и документами. На основе оценок релевантности определяется множество результатов, которое затем возвращается пользователям.

Связь между системными сообщениями и подсистемой формирования запроса означает возможность использования результатов поиска пользователями для уточнения информационных потребностей.

Система информационного поиска обычно реализуется на основе соответствующей теоретической модели, в которой описываются ее основные особенности: логические представления документов и запросов, а также алгоритмы вычисления оценки релевантности между ними. В общем случае модель информационного поиска состоит из следующих 4-х компонентов:

$$
\text { Model }=[D, Q, F, R(q, d)] \text {, }
$$

где $\mathrm{D}$ - множество логических представлений документов (логические представления документов являются их упрощенными моделями в поисковых системах); Q - множество логических представлений информационных потребностей (запросов); F - платформа для моделирования документов, запросов и для реализации функции вычисления близости между документами и запросами - функции $\mathrm{R}(\mathrm{d}, \mathrm{q})$.

Подход к обработке документов на синтаксическом уровне в большинстве существующих моделей (например, модель булевого поиска, модель векторного 
пространства, вероятностная модель, модель нечеткого множества, модели обобщенного векторного пространства) вызывает следующие фундаментальные проблемы, которые затрудняют работу пользователей при поиске нужной информации: 1) синонимичность терминов; 2) многозначность терминов.

Кроме того, из-за отсутствия семантических отношений между терминами системы не способны найти документы, которые являются релевантными по смыслу, но не содержат термины запроса. В связи с этой проблемой снижается полнота множества результатов.

Решение этих проблем требует выполнять работу с семантикой документов и представлять документы на более высоком концептуальном уровне с использованием понятий из семантических моделей знаний предметных областей.В дополнение, по результату выполненного обзора и классификация существующих подходов семантического поиска с целью формирования общего представления о данном направлении информационного поиска нами отмечено, что важной особенностью подходов семантического поиска является использование концептуальных представлений документов, которые создаются на основе семантических моделей знаний предметных областей, а среди существующих инструментов представления знаний онтология считается наиболее выразительным. В онтологиях знания предметных областей описываются с помощью иерархий понятий и свойств, а также семантических сетей связанных экземпляров понятий.

Только использование онтологических моделей знаний позволит достигнуть значительного улучшения качества поиска по сравнению с существующими подходами. В связи с этим, несмотря на сложность и трудоемкость создания онтологических моделей, охватывающих области знаний поисковой системы, а также сложность и трудоемкость создания семантических описаний существующих текстов, считается, что семантический поиск на основе онтологий является наиболее перспективным направлением развития методов информационного поиска. 